\title{
Parkinson's Disease: The Emerging Role of Gut Dysbiosis, Antibiotics, Probiotics, and Fecal Microbiota Transplantation
}

\author{
Sudhir K Dutta, ${ }^{1,2}$ Sandeep Verma, ${ }^{1 *}$ Vardhmaan Jain, ${ }^{3}$ Balarama K Surapaneni, ${ }^{4}$ Rakesh Vinayek, ${ }^{1}$ Laila Phillips, ${ }^{1}$ and \\ Padmanabhan P Nair ${ }^{1,5,6}$
}

${ }^{\prime}$ Sinai Hospital, Baltimore, MD, USA; ${ }^{2}$ University of Maryland School of Medicine, Baltimore, MD, USA; ${ }^{3}$ Maulana Azad Medical College, New Delhi, India; ${ }^{4}$ Aventura Hospital and Medical Center, Aventura, FL, USA; ${ }^{5}$ Bloomberg School of Public Health, Johns Hopkins University, Baltimore, MD, USA; and ${ }^{6}$ NonInvasive Technologies LLC, Elkridge, MD, USA

The role of the microbiome in health and human disease has emerged at the forefront of medicine in the 21st century. Over the last 2 decades evidence has emerged to suggest that inflammation-derived oxidative damage and cytokine induced toxicity may play a significant role in the neuronal damage associated with Parkinson's disease (PD). Presence of pro-inflammatory cytokines and T cell infiltration has been observed in the brain parenchyma of patients with PD. Furthermore, evidence for inflammatory changes has been reported in the enteric nervous system, the vagus nerve branches and glial cells. The presence of $\alpha$-synuclein deposits in the post-mortem brain biopsy in patients with PD has further substantiated the role of inflammation in PD. It has been suggested that the $\alpha$-synuclein misfolding might begin in the gut and spread "prion like" via the vagus nerve into lower brainstem and ultimately to the midbrain; this is known as the Braak hypothesis. It is noteworthy that the presence of gastrointestinal symptoms (constipation, dysphagia, and hypersalivation), altered gut microbiota and leaky gut have been observed in PD patients several years prior to the clinical onset of the disease. These clinical observations have been supported by in vitro studies in mice as well, demonstrating the role of genetic ( $\alpha$-synuclein overexpression) and environmental (gut dysbiosis) factors in the pathogenesis of PD. The restoration of the gut microbiome in patients with PD may alter the clinical progression of PD and this alteration can be accomplished by carefully designed studies using customized probiotics and fecal microbiota transplantation.

(J Neurogastroenterol Motil 2019;25:363-376)

Key Words

Dysbiosis; Fecal microbiota transplantation; Microbiota; Parkinson disease; Probiotics

\section{Introduction}

Parkinson's disease (PD) is a debilitating neuromotor disorder affecting the nigrostriatal pathway in the midbrain. In the United States, PD is the second most common neurodegenerative disease. It has an incidence of 14 per 100000 people in the total population, however, the incidence increases to 160 per 100000 in individuals 65 years and older. ${ }^{1}$ The lifetime risk of the disease is estimated to be $4.4 \%$ for men and $3.7 \%$ for women in the United States at birth. $^{2}$ An estimated 1 million people are affected by this progressive disorder of the central nervous system (CNS). Globally, it is estimated that over 3 million patients may suffer from PD.,

$\mathrm{PD}$ is characterized by an array of motor symptoms ranging

Received: March 5, 2019 Revised: May 17, 2019 Accepted: June 24, 2019

(5) This is an Open Access article distributed under the terms of the Creative Commons Attribution Non-Commercial License (http://creativecommons. org/licenses/by-nc/4.0) which permits unrestricted non-commercial use, distribution, and reproduction in any medium, provided the original work is properly cited.

${ }^{*}$ Correspondence: Sandeep Verma, MD, MBBS

Sinai Hospital, 2434 W Belvedere Ave, Building C, Baltimore, MD 21215, USA

Tel: +1-443-453-6021, Fax: +1-410-601-5757,E-mail: docsandeepverma@gmail.com 
from tremors, rigidity, bradykinesia (often akinesia), and postural abnormalities (characterized by a shuffling gait). Very common neuropsychiatric symptoms include depression, anxiety, apathy, cognitive decline, dementia, and psychosis. In addition, many nonneurological and non-motor symptoms of the gastrointestinal (GI) tract such as constipation, bloating, urinary incontinence, anosmia, and blunted affect are also observed. ${ }^{5-7}$

Histopathologically, the disease is associated with an accumulation of Lewy bodies, which are intra-cytoplasmic eosinophilic deposits composed of a misfolded protein, $\alpha$-synuclein, in the basal ganglia neurons, especially in the caudate nucleus and the putamen. ${ }^{5}$ Based on available evidence, it has been postulated that depletion of the dopaminergic neurons in the substantia nigra in the midbrain results in a defect in the thalamic signaling to the cerebral cortex. ${ }^{5}$ This presumably results in the characteristic signs and symptoms of PD. The multiple factors associated with the pathogenesis and progression of $\mathrm{PD}$ are summarized in Table 1.

The currently available treatment modalities for PD fall under medical, surgical or supplementary therapies. The cornerstone of medical therapies for the treatment of $\mathrm{PD}$ include the combination of levodopa-carbidopa, which increases dopamine levels for neural transmission in the diseased areas of the brain. ${ }^{16}$ Additional pharmacological options include synthetic dopamine receptor agonists (eg, ropinirole and pramipexole) which stimulate dopamine receptor and
catechol-O-methyl transferase inhibitors, and reduce dopamine and levodopa degradation outside the brain to increase its availability at the site of action at the midbrain. ${ }^{16}$ Similarly, monoamine oxidase inhibitors (eg, selegiline and rasagiline) prolong the duration of action of dopamine and its analogues, and leads to an improvement in the symptoms of PD. ${ }^{16}$

The current surgical options available for the treatment of PD are limited and rarely used. However, surgery is considered for patients who have fluctuating responses to levodopa treatment, intractable tremor, or dyskinesia. Deep brain stimulation is a novel surgical method that involves an implant of electrodes in certain areas of the brain such as the sub-thalamic nuclei, and a pulse generator similar to an artificial pacemaker located just below the clavicle. ${ }^{17}$ Once in place, the pacemaker generates impulses to stimulate the implanted electrodes that in turn block the subthalamic signals, which improves motor symptoms of PD. ${ }^{17}$

The role of diet and nutritional supplements in the management of PD has also been studied. Mischley et $\mathrm{al}^{18}$ conducted a cross-sectional analysis study conducted in 1053 patients, which concluded that foods associated with a reduction in the progression of PD include fresh (uncanned or non-frozen) vegetables, fruits, nuts, seeds, herbs, non-fried fish, olive oil, coconut oil, and spices $(P<0.05)$. Supplements enacting a similar reduction in $\mathrm{PD}$ progression included $\mathrm{CoQ} 10$ and fish oil $(P<0.05)$. Foods associ-

Table 1. Factors Associated With Pathogenesis and Progression of Parkinson's Disease

\begin{tabular}{|c|c|c|c|}
\hline Phenomenon & Description & Degree of Association & Reference \\
\hline Loss of dopaminergic activity & $\begin{array}{l}\text { Silencing of neuronal dopamine } \\
\text { generation in the substantia nigra }\end{array}$ & $\begin{array}{l}\text { High: proximate cause, potentially } \\
\text { reversible }\end{array}$ & Siderowf and Stern, ${ }^{8} 2003$ \\
\hline Inclusion of Lewy bodies & Aggregation of $\alpha$-synuclein & $\begin{array}{l}\text { High: appears in the gut in the } \\
\text { prodromal phase }\end{array}$ & \\
\hline Sex differences & Greater prevalence among men & High: brain sex dimorphism & Gillies et al, ${ }^{9} 2014$ \\
\hline Gut dysbiosis & Prodromal symptoms of PD & $\begin{array}{l}\text { High: strong association with the } \\
\text { microbiome }\end{array}$ & Minato et al, ${ }^{10} 2017$ \\
\hline Aging & Advancing age & High-Moderate & \\
\hline Environmental factors & $\begin{array}{l}\text { Exposure to neurotoxins in the gut lead } \\
\text { to loss of dopaminergic activity }\end{array}$ & Moderate & Yadav et al, ${ }^{11} 2013$ \\
\hline Parkin ligase & $\begin{array}{l}\text { Loss linked to mutations in the PRKN } \\
\text { gene }\end{array}$ & Moderate: familial form of PD & Kitada et al, ${ }^{12} 1998$ \\
\hline $\begin{array}{l}\text { Glucagon-like peptide } \\
\text { synthetic homolog: exenatide }\end{array}$ & $\begin{array}{l}\text { Insulinotropic gut hormone; may have a } \\
\text { protective function in the gut-brain axis }\end{array}$ & Moderate: ameliorates PD symptoms & Kim et al, ${ }^{13} 2017$ \\
\hline $\begin{array}{l}S R Y \text { gene in the male } \mathrm{Y} \\
\text { chromosome }\end{array}$ & $\begin{array}{l}\text { Regulates expression of tyrosine } \\
\text { hydroxylase, rate-determining step to } \\
\text { dopamine }\end{array}$ & Indeterminate & Dewing et al, ${ }^{14} 2006$ \\
\hline Ultrasound thalamotomy & $\begin{array}{l}\text { Effective in medication-refractory } \\
\text { tremor-dominant PD }\end{array}$ & $\begin{array}{l}\text { Indeterminate: may disrupt } \\
\text { Lewy bodies }\end{array}$ & Bond et al, ${ }^{15} 2017$ \\
\hline
\end{tabular}

PD, Parkinson's disease; PRKN, parkin RBR E3 ubiquitin protein ligase; SRY, sex determining region Y. 
ated with the worsening of $\mathrm{PD}(P<0.05)$ included canned fruits and vegetables, diet and non-diet soda, fried foods, beef, ice cream, yogurt, and cheese. Similarly, iron supplementation was associated with a faster progression of $\mathrm{PD}(P<0.05) .{ }^{18}$ Polyphenols and flavonoids have been studied in a wide range of in vitro and in vivo models of neurological diseases. These nutrients, found in plants and microbes, have showcased a neuroprotective role in PD. ${ }^{19}$ Another prospective study in Sweden was conducted by Yang et $\mathrm{al}^{20}$ in 2 population-based cohorts (38 937 women and 45837 men) to understand dietary antioxidants and the risk of PD. During a 14.9 year follow-up, 1329 PD cases were identified. The intake of vita$\min \mathrm{E}$ and beta-carotene was associated with a lower risk of PD in the identified patients. ${ }^{20}$

\section{Limitations of Current Treatment Modalities for Parkinson's Disease}

Although an array of medical and surgical interventions are available for the treatment of $\mathrm{PD}$, a comprehensive management strategy to prevent the progression of the disease is far from a reality. Most patients on long-term dopamine replacement therapy develop a resurgence of symptoms such as disabling dyskinesia, occasional psychosis, and/or characteristic disease-related symptoms such as tremors and rigidity. ${ }^{21,22}$ Many patients also develop dopamineresistant-motor and non-motor symptoms after years of treatment, and become poor candidates for further medial therapy. Finally, none of these modalities have been known to alter the natural history of the disease after the onset of symptoms. ${ }^{22}$ Therefore, new therapeutic modalities are needed in the future, not only to prevent disease progression but also to find a cure for PD. In this review, we have focused on the potential role of modulation of gut microbiota in an attempt to attenuate associated inflammation in the gut, enteric nervous system (ENS), and CNS. Recent observations linking inflammation in the CNS, ENS, and GI tract to gut dysbiosis have raised the possibility of new treatment modalities in PD. These include cultured or genetically engineered "tailor-made" probiotics and long-term administration of fecal microbiota transplant (FMT) to restore normal gut microbiota to slow the progression of PD.

\section{Natural History of Parkinson's Disease}

$\mathrm{PD}$ is a slowly progressing disorder, but this progression is highly variable from patient to patient. Life expectancy is marginally reduced. ${ }^{23}$ Death is usually the result of complications from impaired movement such as a fall with fracture leading to immobil- ity, aspiration from severe dysphagia, and bowel obstruction from poor gut motility. Prognosis is generally based on favorable indicators, which include prominent tremors without significant rigidity, absence of gait disorder or bradykinesia, normal cognition, and positive attitude. Negative indicators include postural instability and bradykinesia without tremor, recurrent episodes of falling, apathy, cognitive decline, depression and/or anxiety, dysphagia, and orthostatic hypotension. In the last decade, there has been an increase of research demonstrating the benefit of exercise on managing the motor symptoms of PD. There is a need for early identification of these indicators to provide therapy that can modulate the disease process favorably. Probiotics and FMT may play a role in reducing the progression of the disease and improve psychomotor and neurological symptoms.

\section{Role of Inflammation in the Central Nervous System in Parkinson's Disease}

A possible role of glial cell dysregulation and its association with inflammation has also been demonstrated in the CNS of patients with PD. ${ }^{24}$ Devos et $\mathrm{al}^{25}$ evaluated $19 \mathrm{PD}$ patients and 14 agematched controls to look for inflammatory and glial cell markers in their intestinal biopsies. They found evidence of increased inflammatory cytokines such as IL-6 and IL-1 $\beta$ and enhanced expression of glial cell markers (ie, glial fibrillary acidic protein [GFAP] and SRY-Box 10 [Sox-10]) using real time polymerase chain reaction. These findings have pointed towards the involvement of the gutbrain axis in the pathogenesis of PD. ${ }^{25}$ These investigators however, did not find a correlation between the levels of pro-inflammatory cytokines or glial cell markers with disease severity, GI symptoms or cumulative lifetime dose of L-dopa. ${ }^{25}$ Several factors such as the presence of glial cell markers in the myenteric and Auerbach's plexus in the intestinal mucosa, and increased glial cell dysfunction and oxidative stress in the Substantia Nigra pars compacta of patients of PD provide possible links between the development of inflammation in the nervous system and $\mathrm{PD} .^{24}$

Increased levels of pro-inflammatory cytokines such as IL-6 and TNF- $\alpha$ have been observed in the cerebrospinal fluid of patients with $\mathrm{PD}{ }^{26-28}$ There has been growing evidence to show that oxidative stress and cytokine-dependent toxicity could play a role in the pathogenesis of neuronal damage in the substantia nigra. ${ }^{29,30}$ Brochard et $\mathrm{al}^{29}$ have reported increased infiltration of reactive lymphocytes in 1-methyl-4-phenyl-1,2,3,6-tetrahydropyridine (MPTP) treated mice, which has further strengthened this claim.

A study conducted by Sampson et $\mathrm{al}^{31}$ provides in vivo evi- 
dence to support a similar hypothesis of colonic inflammation in the pathogenesis of PD. The study involved germ-free mice and wild type mice. Each category was further subdivided to either specific pathogen free or $\alpha$-synuclein overexpressing (ASO) mice. A series of tests of gross motor and fine motor function indicated a significantly higher risk of motor impairment and development of disease symptoms in the specific pathogen free and the ASO varieties. ${ }^{31}$ Moreover, it was shown that transplanting fecal microbiota from PD patients demonstrating gut dysbiosis to mice leads to a significantly higher chance of developing disease symptoms as compared to transplanting fecal microbiota from healthy donors. ${ }^{31}$ The risk was significantly higher in ASO varieties as compared to the wild type varieties. The study thus concluded that both genetic (ASO overexpression) and environmental (gut dysbiosis) factors play a role in the pathogenesis of $\mathrm{PD}^{31}$

These emerging pieces of evidence suggest that inflammation may have a substantial role in the development and progression of PD. Furthermore, gut dysbiosis may precede glial cell dysfunction several years before the onset of the disease..$^{25}$

\section{Evidence for the Presence of Inflammation in the Enteric Nervous System in Parkinson's Disease}

The ENS is the intrinsic nervous system of the GI tract that works autonomously. It is comprised of thousands of small ganglia throughout the GI tract. Each ganglion consists of neurons and glial cells but lacks a connective tissue element. The enteric glial cells have been studied extensively for a possible role in pathogenesis of the disease. Studies have shown that enteric glial cells are similar to glial cells present in the CNS of humans both structurally and functionally. ${ }^{22,23}$ As discussed before, these enteric glial cells are immunoreactive to canonical astrocyte markers (GFAP and S100- $\beta$ ). ${ }^{32,33}$ Recent studies suggest that enteric glial cell dysfunction in PD patients may be playing an important role modulating increased gut permeability. Forsyth et $\mathrm{al}^{34}$ conducted a very important study to evaluate changes in the intestinal permeability in PD patients as compared to healthy subjects. In this study, they obtained mucosal biopsies from intestines (sigmoid colon) and used immunochemistry tools to assess bacterial translocation, to detect nitrotyrosine (oxidative stress), and $\alpha$-synuclein. ${ }^{34}$ In addition, they also evaluated serum markers of endotoxin exposure including lipopolysaccharide binding protein (LBP). ${ }^{34}$ The outcome of the study highlighted a significant increase in intestinal permeability in PD patients, which correlated with increased intestinal mucosa staining for Escherichia coli bacteria, nitrotyrosine, as well as serum LBP levels. ${ }^{34}$ Furthermore, there was a strong correlation between increased intestinal permeability with intestinal $\alpha$-synuclein (hallmark of PD) with staining of gram negative bacteria and tissue oxidative stress, suggesting a role of gut leakiness in pathogenesis of $\mathrm{PD} .^{34}$ These findings appear to support the Braak's hypothesis, that PD may be triggered by an unknown agent that breaches intestinal epithelial barrier to induce $\alpha$-synuclein aggregation in ENS. Furthermore, in this hypothesis, he suggested that $\alpha$-synuclein pathology appears to propagate in a prion-like manner to the CNS via the vagal preganglionic innervation of the gut. ${ }^{35,36}$

There are 2 major sets of ganglia found in the ENS: the myenteric ganglia and the submucosal ganglia. The parasympathetic and sympathetic nervous systems send input to the ENS and receive input from afferent nerve fibers via the vagus nerve and spinal afferent pathways. Due to these 2-way pathways, the ENS interacts with sympathetic prevertebral ganglia and the CNS. ${ }^{37}$

The increasing interest in the role of non-neurological factors in the pathogenesis of PD stems from the fact that only $10 \%$ of PD cases have a strong genetic predisposition. ${ }^{38}$ To date there is growing evidence of the role of environmental and intrinsic host factors in its pathophysiology. ${ }^{31}$ The "gut microbiota" refers to the totality of the microbial species residing in our gut, including bacteria, fungi, archaea, and viruses. The current data suggest that there are over 100 trillion species of microbes harbored by the gut environment. ${ }^{39}$ Over a period of time the gut microbiome signature of each individual becomes unique due to environmental and host factors. ${ }^{40}$ The gut-brain axis is believed to be a bidirectional signaling pathway between the gut and the brain. ${ }^{41-44}$ The intestinal barrier consists of multiple layers that include the gut flora and external mucus layer, epithelial layer, and lamina propria. In addition to its role in absorbing nutrients, the epithelial layer serves as a physical barrier against invading pathogens due to tight junctions between epithelial cells. The normal gut microbiome is non-pathogenic in nature, and its members coexist with the enterocytes, providing additional support in intestinal barrier function. Changes in the gut microbiome can potentially play a role in many neurological diseases and it has been reported that GI symptoms (constipation, dysphagia, hypersalivation and swallowing disorders) along with gut dysbiosis and leaky gut precede the onset of symptoms in autism, anxiety, depression and PD by 5-10 years. ${ }^{44-46}$

Intestinal barrier impairment leads to a spread of bacteria across the tight junctions into the mesenteric lymphoid tissue. ${ }^{47}$ This introduces new bacterial products to the lymphoid tissue, thereby activating mucosal immune cells to release inflammatory cytokines 
and vagal nervous system activation. ${ }^{47}$ These cascades of events may lead to the release of neuroactive peptides that modulate the CNS and ENS. ${ }^{48,49}$ Many patients suffer from GI symptoms such as constipation and bloating long before the onset of the hallmark motor symptoms of PD. ${ }^{50}$ Several researchers hypothesize that gut inflammation and deposition of aberrant $\alpha$-synuclein fibrils in the ENS initiate the process that leads to a retrograde spread via the vagal and the glossopharyngeal nerve trunks to the neuronal tissue in the CNS (Figure). ${ }^{51,52}$ This is supported by the fact that $\alpha$-synuclein deposits have been found early on, in the ENS of individuals with PD. ${ }^{53}$ However, a recent study by Lee et $a l,{ }^{54}$ in patients with $\mathrm{PD}(\mathrm{n}=35)$ compared deposition of $\alpha$-synuclein in intestinal mucosal ENS as compared to controls $(n=52)$ to assess GI dysfunction. In this study, the proportion of self-reported constipation and functional constipation was significantly higher in PD patients than in controls $(P<0.05)$. $^{54}$ This study did not demonstrate any association between $\alpha$-synuclein deposition in ENS and functional impairment of affected segment of the gut (in mucosal biopsy). ${ }^{54}$ These findings suggest that additional studies are needed to elucidate the role of different $\alpha$-synuclein strains in ENS of human subjects and their potential clinical implications. Furthermore, the role of the vagus nerve and its branches in the pathogenesis of $\mathrm{PD}$ has recently been brought into focus. In a retrospective study, Svensson et $\mathrm{al}^{55}$ demonstrated that individuals undergoing bilateral truncal vagotomy $(\mathrm{n}=5339)$ and superselective vagotomy $(\mathrm{n}=$
5870) were at a reduced risk of developing $\mathrm{PD}$ as compared to the general population ( $\mathrm{n}=66711$ and $\mathrm{n}=60500$, respectively). This observation supports a strong association of vagal nerve fibers with the pathogenesis of PD.

\section{Mediators of Inflammation in the Central Nervous System and Enteric Nervous System in Parkinson's Disease}

\section{Central Nervous System Lymphatics}

Louveau et $\mathrm{al}^{56}$ discovered a network of lymphatic vessels lining dural sinuses carrying both fluid and immune cells from cerebrospinal fluid. This observation opens the door to the possibility that cytokines from the GI tract may interact more with the CNS than previously understood. Any microbial dysbiosis that potentially triggers an inflammatory cascade in the CNS can potentially cause dysfunction of the immune system, leading to the development of neurodegenerative diseases like PD.

\section{Toll-like Receptors and $\alpha$-Synuclein}

There has been increased interest in the recognition of the role of Toll-like receptors (TLRs) in the pathogenesis of PD. TLRs recognize conserved motifs found in microorganisms and initiate a

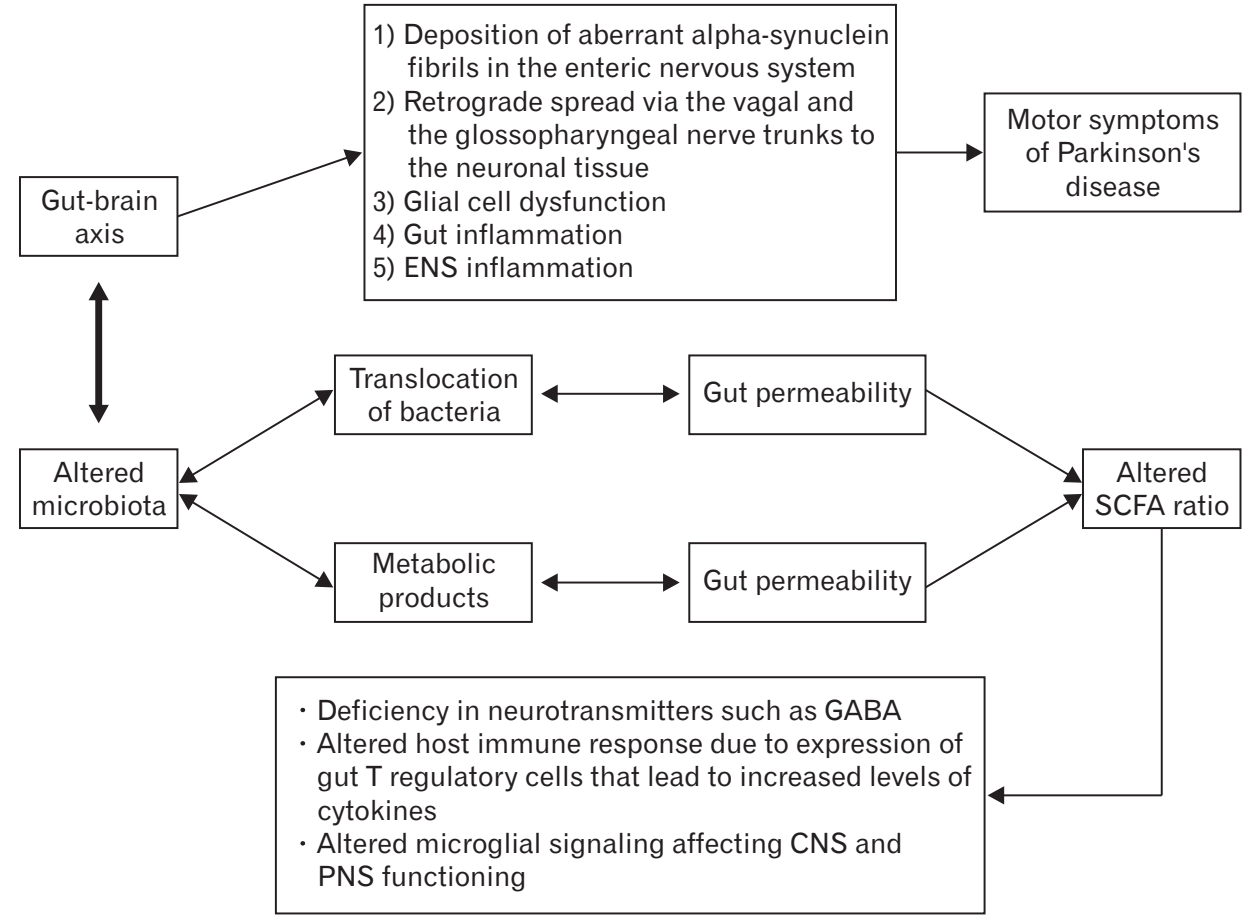

Figure. Bidirectional gut-brain axis pathophysiological cascasde in the development of Parkinson's disease. ENS, enteric nervous system; SCFA, short-chain fatty acid; GABA, gammaaminobutyric acid; CNS, central nervous system; PNS, peripheral nervous system. 
cascade of immunological responses. TLRs are class of mammalian receptors that play a role in innate immunity and inflammation. ${ }^{57}$ Any overstimulation of the innate immune system due to stimuli like gut dysbiosis, along with "leaky gut" may provoke local and systemic inflammation, leading to enteric neuroglial activation and triggering of $\alpha$-synuclein pathology. There are 13 identified TLRs in mammals, and ten have been noted in humans. TLRs are found in a variety of human tissues including immune system related cell types such as B cells, mast cells, NK cells, T-reg cells, macrophages, monocytes, dendritic cells, neutrophils, and basophils, along with non-immune cells such as epithelial cells and endothelial cells. ${ }^{58,59}$ They are also present on neurons and glial cells in both the PNS and CNS in humans. ${ }^{60}$ TLRs are involved in the activation of several downstream pathways of inflammation, including the nuclear factor-kappa B (NF-kB) pathway, mitogen-activated protein kinases (MAPK) pathway, and/or the interferon-regulatory factor (IRF) signaling pathway. ${ }^{61,62} \alpha$-synuclein is a small protein of the synuclein family of proteins. ${ }^{63}$ It is encoded by the SCNA gene, present on the long arm of chromosome 4 in humans ${ }^{64}$ and it is highly expressed in neural tissues, especially the CNS in humans, and primarily at presynaptic terminals. ${ }^{65} \alpha$-synuclein is considered to act as a "brake" in dopaminergic neurotransmission in humans. ${ }^{66}$ It shows dynamic changes in its conformation with relation to its environment and is considered to behave as a "natively unfolded" protein. $\alpha$-synuclein is highly soluble and intrinsically disordered under normal conditions. ${ }^{67}$ Aggregation of $\alpha$-synuclein is known to cause synucleinopathies, which are types of neurodegenerative disorders, including PD. ${ }^{68}$ Fellner et $\mathrm{al}^{69}$ showed in murine model studies that TLR4 interacts with $\alpha$-synuclein, initiating microglial responses, which are associated with $\mathrm{PD}$. In a transgenic mouse model study, the TLR4 ablation was found to be associated with impairment of the microglial phagocytic response to $\alpha$-synuclein. ${ }^{69}$ This abnormality led to an accumulation of $\alpha$-synuclein and more dopaminergic degeneration in the substantia nigra, suggesting a critical role of TLR4 in the clearance of $\alpha$-synuclein. ${ }^{70}$

\section{Molecular Mimicry}

Molecular mimicry is a mechanism where foreign antigen(s) share nucleotide sequence or structural similarities with selfantigen(s). It has been widely studied in pathogenesis of viral diseases such as measles, herpes simplex virus, hepatitis B virus and in pathogenesis of autoimmune diseases. Neurodegenerative disorders like PD are characterized by deposition of $\alpha$-synuclein in basal ganglia and putamen in CNS. It has been proposed by Friedland, that misfolding of these neuronal proteins found in $\mathrm{PD}$, maybe triggered by molecular mimicry induced template cross-seeding similar to transmission of prion diseases in CNS. ${ }^{71}$ Cross-seeding is a phenomenon in which an endogenous or an exogenous protein may induce beta sheet misfolding of a host protein with a different primary structure. ${ }^{72}$ Spreading of these misfolded proteins seems to occur along neuronal connections through axonal membranes similar to prion disease like cell to cell spread with neuronal connectivity. ${ }^{72}$ The basis of molecular mimicry in PD may originate from the fact that the gut bacteria are known to produce extracellular amyloid, which can lead to activation of innate immune system. These events can potentially lead to priming of neuroinflammation and disease pathogenesis in CNS in PD patients via pathway of molecular mimcry. ${ }^{73-75}$

\section{Inflammaging}

Ageing is associated with increased low grade chronic inflammation, called "inflammaging." It is characterized by the presence of latent infections with viruses such as cytomegalovirus along with increased circulating levels of inflammatory markers like TNF- $\alpha$, IL-6, and C-reactive protein. ${ }^{76}$ It appears with advancing age, microbiota composition in the gut changes as compared to young controls. ${ }^{77}$ And, these alterations in gut microbiota may be associated with higher levels of inflammatory mediators such as IL-6 and IL8. ${ }^{78}$ Therefore it follows, altered gut microbiota in elderly may play a role in pathogenesis of $\mathrm{PD}$ via inflammaging.

It seems quite likely that gut dysbiosis associated with dietary changes may lead to the activation of various inflammatory cascades in the ENS, CNS, and vagus nerve, resulting in an accumulation of $\alpha$-synuclein with subsequent dopaminergic degeneration in the substantia nigra.

\section{Development of Disease-associated Gut Dysbiosis}

Bacterial density varies markedly in the different parts of the human GI tract. The proximal GI tract is generally populated by Streptococcaceae and Lactobacillaceae $\left(10^{1}-10^{3}\right)$, while the distal small bowel is home to Lactobacillaceae, Erysipelotrichaceae and Enterobacteriaceae $\left(10^{4}-10^{7}\right)$. The colon is populated by bacterial families including Bacteriodaceae, Ruminococcaceae, Prevotellaceae, and Clostridiaceae $\left(10^{11}-10^{12}\right) \cdot{ }^{79-84}$ The stomach contains commensal species from the families Lactobacillaceae and Streptococcaceae in the epithelial layer. ${ }^{79-84}$ In the small intestine, Lactobacillaceae and segmented filamentous bacteria are the most abundant. ${ }^{79-84}$ The outer mucous layer of the colon has an abundance of Akkermansia 
muciniphila and Bifidobacteriaceae, while the epithelium within the crypts hosts Bacteroides fragilis and Actinobacterium spp. ${ }^{79-84}$

Gut dysbiosis is the alteration in structural and/or functional configuration of the gut microbiota causing disruption of gut homeostasis. ${ }^{85}$ This homeostasis can be disturbed by several factors such as dietary alterations, antibiotic exposure, infections, disease states, and aging. Scher et $\mathrm{al}^{84}$ studied the gut microbiota in patients of psoriatic arthritis and psoriasis of the skin. There was relative decrease in Coprococcus spp. in both patient groups, while fecal samples from patients with psoriatic arthritis had a significant reduction in Akkermansia, Ruminococcus, and Pseudobutyrivibrio spp. ${ }^{86}$ These results were similar to results of gut dybiosis in patients with inflammatory bowel disease (IBD), suggesting a strong association between gut dysbiosis, disease pathogenesis, and immune response. ${ }^{86}$ Hager et $\mathrm{al}^{87}$ found that patients with Crohn's disease have higher levels of Candida tropicalis, E. coli, and Serratia marcescens as compared to healthy individuals. These organisms worked in symbiosis to form biofilms, which trigger gut inflammatory responses. ${ }^{87}$ Sampson et $\mathrm{al}^{31}$ claim that gut dysbiosis leads to an altered ratio of short-chain fatty acids (SCFA), especially butyrate, and altered microglial signaling in the brain leading to disease development and the appearance of PD-associated motor symptoms. The first study to explore the relation between gut dysbiosis and PD was conducted by Scheperjans et al. ${ }^{88}$ These investigators observed reduced abundance of Prevotellaceae in PD patients and increased Enterobacteriaceae abundance. These alterations in microbiota species in PD patients were associated with postural instability and gait disorder. ${ }^{88}$ Further evidence for the support of gut dysbiosis in PD pathogenesis comes from the fact that microbial species harvested from PD patients showed lower levels of Prevotella, Lactobacillus, Peptostreptococcus, and Butyricicoccus spp. and an increase in Proteus and Enterobacter spp. compared to healthy controls. ${ }^{31}$ Recent studies conducted in Japan suggest the role of certain bacteria in the worsening of PD and associated symptoms. ${ }^{10}$ Low counts of $B$. fragilis were found to be associated with worsening of motivation/ initiative using the Movement Disorder Society-United Parkinson's Disease Rating Scale (MDS-UPDRS) scoring system. ${ }^{10}$ In addition, lower counts of Bifidobacterium were associated with worsening of hallucinations/delusions using the MDS-UPDRS score over a period of 2 years. ${ }^{10}$ The Clostridium coccoides species was found to be high in patients with early $\mathrm{PD}$, while Lactobacillus gasseri has been reported to be high in patients with advanced PD. ${ }^{89}$ As PD advances clinically, there is dysfunction of ENS (dysautonomia) which leads to greater slowing of GI motility, which in turn predisposes $\mathrm{PD}$ patients to small intestinal bacterial overgrowth (SIBO)..$^{90}$
The role of SIBO has been studied by Fasano et al, ${ }^{91}$ who showed that the prevalence of SIBO is higher in patients $(n=33)$ with $\mathrm{PD}$, than in controls $(\mathrm{n}=30)$. Furthermore, in this study, correction of SIBO with an antibiotic (rifaximin $200 \mathrm{mg} 3$ times a day for 7 days) resulted in improvement of GI symptoms along with improvement in motor fluctuations $(P<0.04) .{ }^{91}$ These changes were not associated with the pharmacokinetics of levodopa. ${ }^{91}$ Furthermore, it was observed that occurrence of SIBO was associated with more severe motor fluctuations (particularly delayed on and no-on) of PD. ${ }^{91}$ These motor fluctuations can be attributed to peripheral factors, such as abnormalities of levodopa bioavailability from GI tract, and the malabsorption associated SIBO due to alteration in the composition of chyme. ${ }^{91}$ Furthermore, since levodopa is mostly absorbed from jejunum, SIBO may impair drug absorption due to associated inflammation of the intestinal mucosa or altered metabolism of levodopa by intraluminal bacteria. ${ }^{91}$

Recently, an unusual case of early PD was treated with colchicine and antibiotics, which not only improved constipation, but reduced symptoms associated with PD as well. This isolated, anecdotal case observation suggests a possible link between gut dysbiosis and PD. ${ }^{92}$ Finally, a recent study conducted by Hill-Burns et al ${ }^{93}$ showed a significant disruption of the gut microbiome in PD. The study evaluated 197 cases of PD with matched 130 controls, and findings included significant alterations in the relative abundance of Bifidobacteriaceae, Christensenellaceae, Tissierellaceae, Lachnospiraceae, Lactobacillaceae, Pasteurellaceae, and Verrucomicrobiaceae. $^{93}$

Further insight into the mechanism of involvement of the gutbrain axis has been provided by Bienenstock et al, ${ }^{94}$ who described a link between the deficiency of SCFA such as butyrate and propionate and the deficiency in neurotransmitters such as gamma-aminobutyric acid. In addition they suggested a link between altered host immune response and altered microglial signaling affecting CNS and peripheral nervous system functioning. ${ }^{94}$ More recently, Unger et $\mathrm{al}^{95}$ conducted an age- and sex-matched controlled trial in 34 subjects and 34 controls, demonstrating that the levels of SCFA and the gut microbiome differed significantly between patients with PD and control groups, leading to increased gut dysmotility, decreased neurotransmitter synthesis and ENS dysfunction in the diseased group. In a mouse model, SCFA were also shown to affect the expression of gut T-regulatory cells that lead to increased levels of cytokines like IL-10 and TGF- $\beta$, which play a crucial role in the neuro-immune inflammatory pathway. ${ }^{96}$ Larraufie et al $^{97}$ showed that butyrate increases the TLR-dependent responses and their expression in a cellular model of human enteroendocrine L-cells. 
These findings provide strong evidence supporting the role of gut dysbiosis in patients with $\mathrm{PD}$.

\section{Modulators of Gut Dysbiosis, and the Po- tential Role of Probiotics and Fecal Micro- biota Transplantation in Intestinal and Neu- rological Diseases}

\section{Probiotics}

Probiotics are live microorganisms, delivered in the form of drug, food, supplements, and formula. A typical probiotic is comprised primarily of bacteria that occur naturally in the human gut. When administered in adequate strength and frequency, they may provide health benefits to the host. ${ }^{98}$ Most probiotics available commercially contain Lactobacillus, Bifidobacterium, or Saccharomyces spp. ${ }^{99,100}$ Fujiya et $\mathrm{al}^{101}$ reviewed 20 randomized controlled trials in 1004 subjects who had active IBD (ulcerative colitis [UC] and Crohn's disease), exploring the role of probiotics as a therapeutic modality. Treatment with probiotics demonstrated comparable results in clinical response, remission rate, and maintenance of remission of UC equivalent to mesalazine, but no statistical significance in these parameters was found in patients with Crohn's disease. ${ }^{101}$ More recently, the potential benefits of probiotics have also been studied in irritable bowel syndrome (IBS) in 53 randomized control trials reviewed by Ford et $\mathrm{al}^{102}$ in a total of 5545 patients. Although, patients with IBS who were treated with probiotics had a beneficial effect on global IBS symptoms, however there was no definitive evidence about their efficacy. ${ }^{102}$ Additionally in this review, 5 trials of similar design on the use of rifaximin in non-constipated IBS patients were evaluated, which suggested higher efficacy of rifaximin than placebo. ${ }^{102}$ Barichella et al $^{103}$ studied the effect of probiotics and prebiotic fiber in constipation associated with PD. In this study, 120 patients were randomly assigned $(2: 1)$ to either fermented milk containing prebiotic fiber and probiotics $(n=80)$ or placebo $(n=40)$, once a day for 4 weeks period. ${ }^{103}$ The higher increase in number of complete bowel movements in group on probiotics was observed as compared to placebo $(P=0.002){ }^{103}$ The probiotic was composed of Streptococcus salivarius, subsp. thermophilus, Enterococcus faecium, Lactobacillus rhamnosus GG, Lactobacillus acidophilus, Lactobacillus plantarum, Lactobacillus paracasei, Lactobacillus delbrueckii, subsp. bulgaricus, and Bifidobacterium (fermented milk). ${ }^{103}$ Similarly, a randomized, double-blind placebo-controlled trial was conducted by Tamtaji et al, ${ }^{104}$ to evaluate clinical and metabolic response to probiotic administration in people with PD. In this study, subjects were randomly assigned ( $\mathrm{n}=30$ each group) to receive $8 \times 10^{9} \mathrm{CFU} /$ day probiotic or placebo, for a period of 12 weeks. ${ }^{104}$ Compared with placebo, group taking probiotics had a significant reduction $(P=0.010)$ in MDS-UPDRS (quantitative measure of clinical symptoms in PD) indicating favorable response to probiotic therapy in patients in $\mathrm{PD} .{ }^{104}$ The probotic administered in this study was composed of Lactobacillus acidophilus, Bifidobacterium bifidum, Lactobacillus reuteri, and Lactobacillus fermentum in encaplsulated form. ${ }^{104}$

Messaoudi et $\mathrm{al}^{105}$ studied the psychological effects of members of the Bifidobacterium and Lactobacillus genera when administered as probiotics, the outcome suggesting a reduction in negative mood in healthy individuals. Probiotics considered to confer mental health benefits through interaction with other commensal gut microbiota are known as psychobiotics. They exert anxiolytic and antidepressant effects altering emotional, cognitive, systemic and neural indices. ${ }^{106}$ This novel concept of psychobiotics has been studied in male mice, wherein probiotic administration resulted in a decrease in proinflammatory cytokines and increase in anti-inflammatory cytokines, ultimately demonstrating cognitive and emotional improvement. ${ }^{107,108}$ As previously discussed, low counts of $B$. fragilis and Bifidobacterium have been associated with worsening of PD. ${ }^{10}$

\section{Fecal Microbiota Transplant}

FMT is the process of delivering fecal material from healthy donors to prospective patients in order to reestablish a stable microbiota in the gut. ${ }^{109,110}$ The procedure of FMT has been well described previously. ${ }^{11-116}$ FMT has been shown to be safe and efficacious in the management of recurrent Clostridium difficile infection (RCDI). This has encouraged investigations related to the effects of FMT in other diseases caused or exacerbated by gut dysbiosis. FMT has also been proposed as a treatment modality for IBD. Jacob et $\mathrm{al}^{117}$ studied the efficacy and use of FMT as a novel treatment in patients with UC. In this study, a fecal preparation with high microbial diversity was prepared using stool from 2 donors, and the clinical endpoint was response, remission and mucosal healing at week four. ${ }^{117}$ Seven out of 20 patients who received FMT showed a clinical response, with 3 subjects in remission and 2 demonstrating mucosal healing. ${ }^{117}$ Mucosal healing was assessed by mucosal CD4 $+\mathrm{T}$ cell analysis, which showed reduction in type 1 helper $\mathrm{T}$ cells and regulatory $\mathrm{T}$ cells post-FMT. ${ }^{117}$ Similarly, Costello et $\mathrm{al}^{118}$ reported results from a randomized, double-blinded clinical trial in 73 adults with mild to moderately active UC. Patients were randomized to receive either donor FMT (dFMT; n = 38) or autologous FMT (prepared from their own stool; $\mathrm{n}=$ 
35). ${ }^{118}$ The dFMT sample was a combination of stool from 3 to 4 extensively screened healthy donors and was prepared anaerobically. ${ }^{118}$ The treatment was well tolerated and at the end of 8 weeks, $32 \%$ (12 out of 38 patients) who had received dFMT achieved a primary outcome of steroid-free remission as compared with $9 \%$ (3 out of 35 patients) who had received autologous FMT. ${ }^{118}$ Secondary outcome in the form of clinical response was achieved in 55\% (21 out of 38 patients) of the dFMT treatment group compared with $23 \%$ (8 out of 35 patients) of the autologous FMT group. ${ }^{118}$ At the end of 1 year, $42 \%$ (5 out of 12 patients) who had achieved remission at 8 weeks maintained remission. ${ }^{118}$ There have been 3 additional randomized clinical trials of FMT in UC, which showed similar promising outcomes. ${ }^{119-121}$ The beneficial effects of this therapy have also been explored in IBS. In a double-blinded, randomized, placebo-controlled, parallel-group, single center trial, FMT (n $=55)$ was compared with placebo $(\mathrm{n}=28)$ for symptom relief in 83 patients with IBS. ${ }^{122}$ The patients with IBS who received FMT showed considerable improvement in their clinical presentation as compared to the placebo group, though results were not statistically significant. ${ }^{122}$ Additionally, in a randomized, double-blind placebocontrolled study by Halkjær et al, ${ }^{123}$ FMT failed to provide symptom relief as compared to placebo in patient with IBS. However, the gut microbiota composition changes were observed in FMT group. ${ }^{123}$ The limitation in the study design was inclusion of all IBS subtypes, duration of treatment and quantity of fecal microbiota transplanted to the patient. ${ }^{123}$ Larger studies with better stratification of patients of IBS and standardization of FMT are required to examine the role of FMT in IBS.

More recently, there has been a growing interest of the benefits of FMT in GI as well as non-GI diseases. The evidence for treatment of neurological disorders with FMT is limited. However, more recently, case series of patients of multiple aclerosis (MS), ${ }^{124}$ myoclonus-dystonia, ${ }^{125}$ autism, ${ }^{126,127}$ depression, ${ }^{128,129}$ and chronic fatigue syndrome ${ }^{130}$ successfully treated with FMT have opened new horizons for more promising trials in defining FMT as a potential treatment for such conditions (Table 2). Frémont et $\mathrm{al}^{131}$ published a study of successful cure rate of $70 \%$ patient in a study of 60 cases of chronic fatigue syndrome, also known as myalgic encephalomyelitis, having received FMT. Furthermore, human and animal models have been developed to show a role of gut dysbiosis in the etiopathogenesis of MS. A case report of 3 patients with MS demonstrated marked remission of both diarrheal and neurological symptoms after receiving $\mathrm{FMT}^{124}$

In light of these findings, it is possible that FMT could play a role in the modulation of $\mathrm{PD}$ and its progression. In addition, con-
Table 2. Summary of Neuropsychiatric Disorders Associated With Gut Microbiota Dysbiosis

\begin{tabular}{|c|c|c|}
\hline $\begin{array}{c}\text { Neuropsychiatric } \\
\text { disorder }\end{array}$ & Reference & Study type \\
\hline Parkinson's disease & Borody et al, ${ }^{92} 2009$ & Case report \\
\hline Multiple sclerosis & Borody et al, ${ }^{124} 2011$ & Case report ${ }^{\mathrm{a}}$ \\
\hline Myoclonus-dystonia & Borody et al, ${ }^{125} 2011$ & Case report ${ }^{\mathrm{a}}$ \\
\hline Autism & $\begin{array}{l}\text { Finegold et al, }{ }^{132} 2002 \\
\text { Song et al, }{ }^{133} 2004\end{array}$ & $\begin{array}{l}\text { Observational study } \\
\text { Observational study }\end{array}$ \\
\hline $\begin{array}{l}\text { Chronic fatigue } \\
\text { syndrome }\end{array}$ & $\begin{array}{l}\text { Borody et al, }{ }^{130} 2012 \\
\text { Frémont et al, }{ }^{131} 2013\end{array}$ & $\begin{array}{l}\text { Cohort study }^{\mathrm{a}} \\
\text { Observational study }\end{array}$ \\
\hline
\end{tabular}

${ }^{a} \mathrm{Fecal}$ microbiota transplantation used in these studies.

clusions drawn from the analysis of microbiota present in healthy FMT donor samples could be valuable in identifying microbes that may confer beneficial physical and mental effects on the host. Use of these microbes in the form of probiotics may also be a novel treatment modality for PD.

\section{Role of Fecal Microbiota Transplant in Par- kinson's Disease}

To date, the role of FMT has not been examined in PD patients. The close relationship amongst factors such as gut dysbiosis, increased intestinal permeability and associated neurological dysfunction suggest that the gut microbiota modification may provide a potential therapeutic option in these group of patients. ${ }^{134}$ This suggestion is based on recently published studies which suggest significant alterations in gut microbiota in recipients of FMT. These administrations of FMT in RCDI patients restores the gut microbiome to a profile resembling that of a healthy individual. ${ }^{135}$ We have postulated long term administration of FMT may provide a novel therapeutic modality to patients with $\mathrm{PD}$. The rationale for the efficacy of FMT in human diseases stems from recent reports showing that gut microbial dysbiosis resulting in inflammation and disruption of the tight junctions (known as "leaky gut") leading to the absorption of bacterial toxins and cascade of biochemical, microbial and immunological changes which results in range of both GI and non-GI diseases and disorders. ${ }^{34}$

Based on the growing evidence pointing to a role of gut dysbiosis in the pathogenesis of $\mathrm{PD}$, it seems prudent that additional prospective well controlled clinical trials are conducted for the evaluation of FMT as a treatment for debilitating neurological diseases. 


\section{Ongoing Research}

A clinical trial is in progress to evaluate FMT as a therapeutic modality in the management of PD. ${ }^{136}$ In this trial (US Clinical Trial No. NCT03026231), DuPont ${ }^{136}$ are planning to characterize the intestinal microbiome in PD. Further aims are to evaluate the safety of lyophilized PRIM-DJ2727 given orally, and to identify fecal microbiome changes following weekly administration of this biological preparation in subjects with PD. ${ }^{136}$ Microbial diversity in fecal samples will be indicated by the Shannon Diversity Index, and richness in fecal samples will be indicated by the number of taxonomies per participant and the most abundant phylum in each fecal sample. ${ }^{136}$ Clinically, the study evaluates neurologic function as indicated by the score on MDS-UPDRS and quality of life as indicated by a score on the self-survey Parkinson's Disease Questionnaire 39, and memory as assessed by a score on the Montreal cognitive assessment. ${ }^{136}$ Although the safety, efficacy, and required quantity of lyophilized FMT capsules have been studied in mouse model in the setting of RCDI with an excellent cure rate, ${ }^{137}$ the amount and number of repeated administrations of lyophilized capsules required in humans and for PD need to be further explored in a prospective clinical trial. There is a growing need for well controlled randomized double-blind clinical trials to establish the role of FMT and probiotics in the treatment of not only PD but other chronic degenerative neurological disorders as well.

\section{Summary}

- PD is a neurodegenerative $\alpha$-synucleopathy affecting nigrostriatal pathway in the midbrain, characterized by an array of motor, neuropsychiatric and GI symptoms.

- Recent studies have suggested a link between PD and inflammation in GI tract. Inflammatory changes have been observed in these group of patients of PD in ENS, vagus nerve branches along with changes in the microbiome of the gut.

- Mechanisms which have been demonstrated to play a potential role in pathogenesis of PD include; evidence of inflammation in the CNS and the ENS, along with leaky gut, gut dysbiosis, molecular mimicry, and inflammaging.

- Several studies have linked changes in gut microbiome with associated symptoms of PD as well as UPDRS.

- Probiotics and FMT are being explored as a therapeutic modality in various GI and non-GI disorders with gut dysbiosis.

- Since current pharmacotherapy options are limited in PD patients, we have postulated that long term administration of tailored probiotics and/or FMT may provide a novel noninvasive therapeutic modality to PD patients. However, long term well controlled double blinded clinical trials will be needed to access the clinical efficacy of these therapeutic modalities in PD patients.

\section{Conclusions}

Several lines of evidence point to developing links between the GI microbiome and the CNS in humans. The wide range of evidence extends from (1) an anecdotal case report, wherein a patient with symptoms of PD noted marked improvement on antibiotics presumably due to modulation of his bacterial microbiome; ${ }^{92}$ (2) detection of abnormalities in the GI microbiome (gut dysbiosis) in patients with $\mathrm{PD} ;{ }^{89,92,93}$ and (3) the discovery of inflammatory changes in the intestinal mucosa, ENS, vagus nerve, and the brain of patients with PD. Furthermore, the mouse model studies have substantiated the growing web of links between the pathological changes in the brain of patients with PD and their GI tract and its resident microbiota. These remarkable observations have inspired several studies intended to evaluate the modulatory role of genetically-tailored and scientifically customized probiotics in patients with PD. Additionally, a well-controlled clinical trial of lyophilized FMT capsules is currently in progress in patients with PD. ${ }^{136}$ These studies along with future developments in this field will shed some more light on the emerging complex and intricate relationship between the gut microbiome and the CNS including the human brain and associated disorders.

Acknowledgements: The authors would like to thank Dr Howard Weiss MD, Director of Parkinson's Disease and Movement Disorder programs at the LifeBridge Health Brain and Spine Institute and Associate Professor of Neurology at the Johns Hopkins University School of Medicine, and Dr Tara Dutta MD, Assistant Professor of Neurology at the University of Maryland School of Medicine for their critical review and input for this manuscript. The authors would also like to thank the Harry and Jeanette Weinberg Foundation, the James and Carolyn Frenkil Foundation, the Eric Cowan Fund, and Friedman \& Friedman, LLP for their generous support.

\section{Financial support: None.}

Conflicts of interest: Sudhir K Dutta has a US patent pending and Padmanabhan P Nair is the ceo of Non-invasive Technology, 


\section{LLP.}

Author contributions: Sudhir K Dutta: design and components of manuscript and first draft; Sandeep Verma: additions and revisions in manuscript, figure, and tables, along with critical review of literature on probiotics and FMT; Vardhmaan Jain, initial references and literature search; Balarama K Surapaneni: initial references and literature search; Rakesh Vinayek: critical review of literature on probiotics and FMT; Padmanabhan P Nair: review and critical assessment of technology used in various papers, tables, and figure; and Laila Phillips: grammatical assessment and help in bibliography.

\section{References}

1. Hirtz D, Thurman DJ, Gwinn-Hardy K, Mohamed M, Chaudhuri AR, Zalutsky R. How common are the "common" neurologic disorders? Neurology 2007;68:326-337.

2. Elbaz A, Bower JH, Maraganore DM, et al. Risk tables for parkinsonism and Parkinson's disease. J Clin Epidemiol 2002;55:25-31.

3. Tysnes OB, Storstein A. Epidemiology of Parkinson's disease. J Neural Transm 2017;124:901-905.

4. Nalls MA, Pankratz N, Lill CM, et al. Large-scale meta-analysis of genome-wide association data identifies six new risk loci for Parkinson's disease. Nat Genet 2014;46:989-993.

5. Kalia LV, Lang AE. Parkinson's disease. Lancet 2015;386:896-912.

6. Jankovic J. Parkinson's disease: clinical features and diagnosis. J Neurol Neurosurg Psychiatry 2008;79:368-376.

7. Pfeiffer RF. Non-motor symptoms in Parkinson's disease. Parkinsonism Relat Disord 2016;22:S119-S122.

8. Siderowf A, Stern M. Update on Parkinson disease. Ann Intern Med 2003;138:651-658.

9. Gillies GE, Pienaar IS, Vohra S, Qamhawi Z. Sex differences in Parkinson's disease Front Neuroendocrinol 2014;35:370-384.

10. Minato T, Maeda T, Fujisawa Y, et al. Progression of Parkinson's disease is associated with gut dysbiosis: two-year follow-up study. PLoS One 2017;12:e0187307.

11. Yadav S K, Prakash J, Chouhan S, Singh SP. Mucuna pruriens seed extract reduces oxidative stress in nigrostriatal tissue and improves neurobehavioral activity in paraquat-induced parkinsonian mouse model. Neurochem Int 2013;62:1039-1047.

12. Kitada T, Asakawa S, Hattori $\mathrm{N}$ et al. Mutations in the parkin gene cause autosomal recessive juvenile parkinsonism. Nature 1998;392:605-608.

13. Kim DS, Choi HI, Wang Y, Luo Y, Hoffer BJ, Greig NH. A new treatment strategy for Parkinson's disease through the gut-brain axis: the glucagon-like peptide-1 receptor pathway. Cell Transplant 2017;26:15601571 .

14. Dewing P, Chiang CW, Sinchak K, et al. Direct regulation of adult brain function by the male-specific factor SRY. Curr Biol 2006;16:415-420.

15. Bond AE, Shah BB, Huss DS, et al. Safety and efficacy of focused ul- trasound thalamotomy for patients with medication-refractory, tremordominant Parkinson disease: a randomized clinical trial. JAMA Neurol 2017;74:1412-1418.

16. Parkinson's Disease Information Page. NIH National Institute of Neurological Disorders and Stroke. Available from URL: https:/www.ninds. nih.gov/Disorders/All-Disorders/Parkinsons-Disease-Information-Page (accessed 17 January, 2019).

17. Okuma Y. Practical approach to freezing of gait in Parkinson's disease. Pract Neurol 2014;14:222-230.

18. Mischley LK, Lau RC, Bennett RD. Role of diet and nutritional supplements in Parkinson's disease progression. Oxid Med Cell Longev 2017;2017:6405278.

19. Carrera I, Cacabelos R. Current drugs and potential future neuroprotective compounds for Parkinson's disease. Curr Neuropharmacol 2019;17:295-306

20. Yang F, Wolk A, Håkansson N, Pedersen NL, Wirdefeldt K. Dietary antioxidants and risk of Parkinson's disease in two population-based cohorts. Mov Disord 2017;32:1631-1636.

21. Rana AQ, Ahmed US, Chaudry ZM, Vasan S. Parkinson's disease: a review of non-motor symptoms. Expert Rev Neurother 2015;15:549-562.

22. Rascol O, Payoux P, Ory F, Ferreira JJ, Brefel-Courbon C, Montastruc JL. Limitations of current Parkinson's disease therapy. Ann Neurol 2003;53(suppl 3):S3-S12; discussion S12-S15.

23. Harrison TR, Kasper DL, Longo DL, Jameson JL, Loscalzo J. Chapter 183: Parkinson's disease. In: Harrison's Manual of Medicine, 19th ed. New York: McGraw Hill Education Medicine 2016:976-981.

24. Damier P, Hirsch EC, Zhang P, Agid Y, Javoy-Agid F. Glutathione peroxidase, glial cells and Parkinson's disease. Neuroscience 2013;52:1-6.

25. Devos D, Lebouvier T, Lardeux B, et al. Colonic inflammation in Parkinson's disease. Neurobiol Dis 2013;50:42-48.

26. Mogi M, Harada M, Kondo T, et al. Interleukin-1 beta, interleukin-6, epidermal growth factor and transforming growth factor-alpha are elevated in the brain from parkinsonian patients. Neurosci Lett 1994;180:147150 .

27. Mogi M, Harada M, Riederer P, Narabayashi H, Fujita K, Nagatsu T. Tumor necrosis factor-alpha (TNF-alpha) increases both in the brain and in the cerebrospinal fluid from parkinsonian patients. Neurosci Lett 1994;165:208-210.

28. Reale M, Iarlori C, Thomas A, et al. Peripheral cytokines profile in Parkinson's disease. Brain Behav Immun 2009;23:55-63.

29. Brochard V, Combadière B, Prigent A, et al. Infiltration of CD4+ lymphocytes into the brain contributes to neurodegeneration in a mouse model of Parkinson disease. J Clin Invest 2009;119:182-192.

30. McGeer PL, Itagaki S, Boyes BE, McGeer EG. Reactive microglia are positive for HLA-DR in the substantia nigra of Parkinson's and Alzheimer's disease brains. Neurology 1988;38:1285-1291.

31. Sampson TR, Debelius JW, Thron T, et al. Gut microbiota regulate motor deficits and neuroinflammation in a model of Parkinson's disease. Cell 2016;167:1469-1480, e12.

32. Jessen KR, Mirsky R. Glial cells in the enteric nervous system contain glial fibrillary acidic protein. Nature 1980;286:736-737.

33. Hanani M, Francke M, Härtig W, et al. Patch-clamp study of neurons 
and glial cells in isolated myenteric ganglia. Am J Physiol Gastrointest Liver Physiol 2000;278:G644-G651.

34. Forsyth CB, Shannon KM, Kordower JH, et al. Increased intestinal permeability correlates with sigmoid mucosa alpha-synuclein staining and endotoxin exposure markers in early Parkinson's disease. PLoS One 2011;6:e28032.

35. Braak H, de Vos RA, Bohl J, Del Tredici K. Gastric alpha-synuclein immunoreactive inclusions in Meissner's and Auerbach's plexuses in cases staged for Parkinson's disease-related brain pathology. Neurosci Lett 2006;396:67-72.

36. Braak H, Del Tredici K. Potential pathways of abnormal tau and $\alpha$-synuclein dissemination in sporadic Alzheimer's and Parkinson's diseases. Cold Spring Harb Perspect Biol Published Online First: 31 Aug 2016. doi: 10.1101/cshperspect.a023630.

37. Furness JB. Disorders of motility and secretion and therapeutic targets in the enteric nervous system. In: Furness JB, ed. The enteric nervous system. Victoria: Blackwell Publishing, Inc. 2006:274.

38. Nalls MA, Bras J, Hernandez DG et al. NeuroX, a fast and efficient genotyping platform for investigation of neurodegenerative diseases. Neurobiol Aging 2015;36:1605, e7-e12.

39. Ley RE, Peterson DA, and Gordon JI. Ecological and evolutionary forces shaping microbial diversity in the human intestine. Cell 2006;124:837848.

40. Nuriel-Ohayon M, Neuman H, Koren O. Microbial changes during pregnancy, birth, and infancy. Front Microbiol 2016;7:1031.

41. Mayer EA. Gut feelings: the emerging biology of gut-brain communication. Nat Rev Neurosci 2011;12:453-466.

42. Cryan JF, O'Mahony SM. The microbiome-gut-brain axis: from bowel to behavior. Neurogastroenterol Motil 2011;23:187-192.

43. De Palma G, Collins SM, Bercik P, Verdu EF. The microbiota-gut-brain axis in gastrointestinal disorders: stressed bugs, stressed brain or both? J Physiol 2014;592:2989-2997.

44. Yarandi SS, Peterson DA, Treisman GJ, Moran TH, Pasricha PJ. Modulatory effects of gut microbiota on the central nervous system: how gut could play a role in neuropsychiatric health and diseases. J Neurogastroenterol Motil 2016;22:201-212.

45. Chen X, D'Souza R, Hong ST. The role of gut microbiota in the gutbrain axis: current challenges and perspectives. Protein Cell 2013;4:403414.

46. Fasano A, Visanji NP, Liu LW, Lang AE, Pfeiffer RF. Gastrointestinal dysfunction in Parkinson's disease. Lancet Neurol 2015;14:625-639.

47. Dicksved J, Schreiber O, Willing B, et al. Lactobacillus reuteri maintains a functional mucosal barrier during DSS treatment despite mucus layer dysfunction. PLoS One 2012;7:e46399.

48. Gareau MG, Silva MA, Perdue MH. Pathophysiological mechanisms of stress-induced intestinal damage. Curr Mol Med 2008;8:274-281.

49. Maes M. The cytokine hypothesis of depression: inflammation, oxidative \& nitrosative stress (IO\&NS) and leaky gut as new targets for adjunctive treatments in depression. Neuro Endocrinol Lett 2008;29:287-291.

50. Ueki A, Otsuka M. Life style risks of Parkinson's disease: association between decreased water intake and constipation. J Neurol 2004;251(suppl 7):vii18-vii23.
51. Kelly LP, Carvey PM, Keshavarzian A, et al. Progression of intestinal permeability changes and alpha-synuclein expression in a mouse model of Parkinson's disease. Mov Disord 2014;29:999-1009.

52. Nair AT, Ramachandran V, Joghee NM, Antony S, Ramalingam G. Gut microbiota dysfunction as reliable non-invasive early diagnostic biomarkers in the pathophysiology of Parkinson's disease: a critical review. J Neurogastroenterol Motil 2018;24:30-42.

53. Beach TG, Adler CH, Sue LI, et al. Multi-organ distribution of phosphorylated $\alpha$-synuclein histopathology in subjects with Lewy body disorders. Acta Neuropathol 2010;119:689-702.

54. Lee HJ, Jung KW, Chung SJ, et al. Relation of enteric $\alpha$-synuclein to gastrointestinal dysfunction in patients with Parkinson's disease and in neurologically intact subjects. J Neurogastroenterol Motil 2018;24:469478.

55. Svensson E, Horváth-Puhó E, Thomsen RW, et al. Vagotomy and subsequent risk of Parkinson's disease. Ann Neurol 2015;78:522-529.

56. Louveau A, Smirnov I, Keyes TJ, et al. Structural and functional features of central nervous system lymphatic vessels. Nature 2015;523:337-341.

57. Mogensen TH. Pathogen recognition and inflammatory signaling in innate immune defenses. Clin Microbiol Rev 2009;22:240-273.

58. Brun P, Gobbo S, Caputi V et al. Toll like receptor-2 regulates production of glial-derived neurotrophic factors in murine intestinal smooth muscle cells. Mol Cell Neurosci 2015;68:24-35.

59. Préhaud C, Mégret F, Lafage M, Lafon M. Virus infection switches TLR-3-positive human neurons to become strong producers of beta interferon. J Virol 2005;79:12893-12904.

60. Okun E, Griffioen KJ, Mattson MP. Toll-like receptor signaling in neural plasticity and disease. Trends Neurosci 2011;34:269-281.

61. Kawasaki T, Kawai T. Toll-like receptor signaling pathways. Front Immunol 2014;5:461.

62. Takeuchi O, Akira S. Pattern recognition receptors and inflammation. Cell 2010;140:805-820.

63. Surguchov A. Molecular and cellular biology of synucleins. In: Jeon KW, ed. International review of cell and molecular biology. Volume 270. Amsterdam: Elsvier Inc. 2008:225-317.

64. Chen X, de Silva HA, Pettenati MJ, et al. The human NACP/ $\alpha$-synuclein gene: chromosome assignment to $4 \mathrm{q} 21.3-\mathrm{q} 22$ and TaqI RFLP analysis. Genomics 1995;26:425-427.

65. Iwai A, Masliah E, Yoshimoto M, et al. The precursor protein of nonA $\beta$ component of Alzheimer's disease amyloid is a presynaptic protein of the central nervous system. Neuron 1995;14:467-475.

66. Fortin DL, Nemani VM, Voglmaier SM, Anthony MD, Ryan TA, Edwards RH. Neural activity controls the synaptic accumulation of $\alpha$-synuclein. J Neurosci 2005;25:10913-10921.

67. Weinreb PH, Zhen W, Poon AW, Conway KA, Lansbury PT Jr. NACP, a protein implicated in Alzheimer's disease and learning, is natively unfolded. Biochemistry 1996;35:13709-13715.

68. Spillatini MG, Schmidt ML, Lee VM, Trojanowski JQ, Jakes R, Goedert M. $\alpha$-synuclein in Lewy bodies. Nature 1997;388:839-840.

69. Fellner L, Irschick R, Schanda K, et al. Toll-like receptor 4 is required for $\alpha$-synuclein dependent activation of microglia and astroglia. Glia 2013;61:349-360. 
70. Stefanova N, Fellner L, Reindl M, Masliah E, Poewe W, Wenning GK. Toll-like receptor 4 promotes $\alpha$-synuclein clearance and survival of nigral dopaminergic neurons. Am J Pathol 2011;179:954-963.

71. Friedland RP. Mechanisms of molecular mimicry involving the microbiota in neurodegeneration. J Alzheimers Dis 2015;45:349-362.

72. Kovacs GG, Breydo L, Green R, et al. Intracellular processing of diseaseassociated $\alpha$-synuclein in the human brain suggests prion-like cell-to-cell spread. Neurobiol Dis 2014;69:76-92.

73. Hufnagel DA, Tükel Ç, Chapman MR. Disease to dirt: the biology of microbial amyloids. PLoS Pathog Published Online Fist: 21 Nov 2013. doi: 10.1371/ournal.ppat.1003740.

74. Schwartz K, Boles BR. Microbial amyloids--functions and interactions within the host. Curr Opin Microbiol 2013;16:93-99.

75. Oli MW, Otoo HN, Crowley PJ, et al. Functional amyloid formation by Streptococcus mutans. Microbiology 2012;158(Pt 12):2903-2916.

76. Frasca D, Blomberg BB. Inflammaging decreases adaptive and innate immune responses in mice and humans. Biogerontology 2015;17:7-19.

77. Yatsunenko T, Rey FE, Manary MJ, et al. Human gut microbiome viewed across age and geography. Nature 2012;486:222-227.

78. Biagi E, Candela M, Turroni S, Garagnani P, Franceschi C, Brigidi P. Ageing and gut microbes: perspectives for health maintenance and longevity. Pharmacol Res 2013;69:11-20.

79. McCracken VJ, Lorenz RG. The gastrointestinal ecosystem: a precarious alliance among epithelium, immunity and microbiota. Cell Microbiol 2001;3:1-11.

80. Sartor RB. Gut microbiota: optimal sampling of the intestinal microbiota for research. Nat Rev Gastroenterol Hepatol 2015;12:253-254.

81. Simrén M, Barbara G, Flint HJ, et al. Intestinal microbiota in functional bowel disorders: a Rome foundation report. Gut 2013;62:159-176.

82. O'Hara AM, Shanahan F. The gut flora as a forgotten organ. EMBO Rep 2006;7:688-693.

83. Swidsinski A, Weber J, Loening-Baucke V, Hale LP, Lochs H. Spatial organization and composition of the mucosal flora in patients with inflammatory bowel disease. J Clin Microbiol 2005;43:3380-3389.

84. Albenberg L, Esipova TV, Judge CP, et al. Correlation between intraluminal oxygen gradient and radial partitioning of intestinal microbiota. Gastroenterology 2014;147:1055-1063, e8.

85. Sommer F, Bäckhed F. The gut microbiota—masters of host development and physiology. Nat Rev Microbiol 2013;11:227-238.

86. Scher JU, Ubeda C, Artacho A, et al. Decreased bacterial diversity characterizes an altered gut microbiota in psoriatic arthritis and resembles dysbiosis of inflammatory bowel disease. Arthritis Rheumatol 2015;67:128139.

87. Hager CL, Ghannoum MA. The mycobiome: role in health and disease, and as a potential probiotic target in gastrointestinal disease. Dig Liver Dis 2017;49:1171-1176.

88. Scheperjans F, Aho V, Pereira PA, at al. Gut microbiota are related to Parkinson's disease and clinical phenotype. Mov Disord. 2015;30:350-358.

89. Hasegawa S, Goto S, Tsuji $\mathrm{H}$, et al. Intestinal dysbiosis and lowered serum lipopolysaccharide-binding protein in Parkinson's disease. PLoS One 2015;10:e0142164.

90. Wüllner U, Schmitz-Hübsch T, Antony G, et al. Autonomic dysfunc- tion in 3414 Parkinson's disease patients enrolled in the German network on Parkinson's disease (KNP e.V.): the effect of ageing. Eur J Neurol 2007;14:1405-1408.

91. Fasano A, Bove F, Gabrielli M, et al. The role of small intestinal bacterial overgrowth in Parkinson's disease. Mov Disord 2013;28:1241-1249.

92. Borody T, Torres M, Campbell J, Hills L, Ketheeswaran S. Treatment of severe constipation improves Parkinson's disease (PD) symptoms: 999. Am J Gastroenterol 2009;104:S367.

93. Hill-Burns EM, Debelius JW, Morton JT, et al. Parkinson's disease and Parkinson's disease medications have distinct signatures of the gut microbiome. Mov Disord 2017;32:739-749.

94. Bienenstock J, Kunze W, Forsythe P. Microbiota and the gut-brain axis. Nutr Rev 2015;73(suppl 1):28-31.

95. Unger MM, Spiegel J, Dillmann KU, et al. Short chain fatty acids and gut microbiota differ between patients with Parkinson's disease and agematched controls. Parkinsonism Relat Disord 2016;32:66-72.

96. Smith PM, Howitt MR, Panikov N, et al. The microbial metabolites, short-chain fatty acids, regulate colonic Treg cell homeostasis. Science 2013;341:569-573.

97. Larraufie P, Doré J, Lapaque N, Blottière HM. TLR ligands and butyrate increase Pyy expression through two distinct but inter-regulated pathways. Cell Microbiol Published Online First: 9 Aug 2016. Doi: 10.1111/ cmi. 12648.

98. Hill C, Guarner F, Reid G, et al. Expert consensus document. The international scientific association for probiotics and prebiotics consensus statement on the scope and appropriate use of the term probiotic. Nat Rev Gastroenterol Hepatol 2014;11:506-514.

99. Andrews JM, Tan M. Probiotics in luminal gastroenterology: the current state of play. Intern Med J 2012;42:1287-1291.

100. Balakrishnan M, Floch MH. Prebiotics, probiotics and digestive health. Curr Opin Clin Nutr Metab Care 2012;15:580-585.

101. Fujiya M, Ueno N, Kohgo Y. Probiotic treatments for induction and maintenance of remission in inflammatory bowel diseases: a meta-analysis of randomized controlled trials. Clin J Gastroenterol 2014;7:1-13.

102. Ford AC, Harris LA, Lacy BE, Quigley EMM, Moayyedi P. Systematic review with meta-analysis: the efficacy of prebiotics, probiotics, synbiotics and antibiotics in irritable bowel syndrome. Aliment Pharmacol Ther 2018;48:1044-1060.

103. Barichella M, Pacchetti C, Bolliri C, et al. Probiotics and prebiotic fiber for constipation associated with Parkinson disease: An RCT. Neurology 2016;87:1274-1280

104. Tamtaji OR, Taghizadeh M, Daneshvar Kakhaki R, et al. Clinical and metabolic response to probiotic administration in people with Parkinson's disease: a randomized, double-blind, placebo-controlled trial. Clin Nutr 2019;38:1031-1035

105. Messaoudi M, Lalonde R, Violle N, et al. Assessment of psychotropiclike properties of a probiotic formulation (Lactobacillus helveticus R0052 and Bifidobacterium longum R0175) in rats and human subjects. Br J Nutr 2011;105:755-764.

106. Sarkar A, Lehto SM, Harty S, Dinan TG, Cryan JF, Burnet PWJ. Psychobiotics and the manipulation of bacteria-gut-brain signals. Trends Neurosci 2016;39:763-781. 
107. Burokas A, Arboleya S, Moloney RD, et al. Targeting the microbiotagut-brain axis: prebiotics have anxiolytic and antidepressant-like effects and reverse the impact of chronic stress in mice. Biol Psychiatry 2017;82:472-487.

108. Savignac HM, Couch Y, Stratford M, et al. Prebiotic administration normalizes lipopolysaccharide (LPS)-induced anxiety and cortical 5-HT2A receptor and IL1- $\beta$ levels in male mice. Brain Behav Immun 2016;52:120-131.

109. Choi HH, Cho YS. Fecal microbiota transplantation: current applications, effectiveness, and future perspectives. Clin Endosc 2016;49:257265.

110. Cui B, Li P, Xu L, et al. Step-up fecal microbiota transplantation (FMT) strategy. Gut Microbes 2016;7:323-328.

111. Rohlke F, Stollman N. Fecal microbiota transplantation in relapsing Clostridium difficile infection. Therap Adv Gastroenterol 2012;5:403-420.

112.Di Bella S, Drapeau C, García-Almodóvar E, Petrosillo N. Fecal microbiota transplantation: the state of the art. Infect Dis Rep 2013;5:e13.

113.Smits LP, Bouter KE, de Vos WM, Borody TJ, Nieuwdorp M. Therapeutic potential of fecal microbiota transplantation. Gastroenterology 2013;145:946-953.

114. Brandt LJ, Aroniadis OC. An overview of fecal microbiota transplantation: techniques, indications, and outcomes. Gastrointest Endosc 2013;78:240-249.

115. Kao D, Roach B, Silva M, et al. Effect of oral capsule- vs colonoscopydelivered fecal microbiota transplantation on recurrent Clostridium difficile infection. JAMA 2017;318:1985-1993.

116. Smillie CS, Sauk J, Gevers D, et al. Strain tracking reveals the determinants of bacterial engraftment in the human gut following fecal microbiota transplantation. Cell Host Microbe 2018;23:229-240, e5.

117. Jacob V, Crawford C, Cohen-Mekelburg S, et al. Single delivery of highdiversity fecal microbiota preparation by colonoscopy is safe and effective in increasing microbial diversity in active ulcerative colitis. Inflamm Bowel Dis 2017;23:903-911.

118. Costello SP, Hughes PA, Waters O, et al. Effect of fecal microbiota transplantation on 8-week remission in patients with ulcerative colitis: a randomized clinical trial. JAMA 2019;321:156-164.

119. Rossen NG, MacDonald JK, de Vries EM, et al. Fecal microbiota transplantation as novel therapy in gastroenterology: a systematic review. World J Gastroenterol 2015;21:5359-5371.

120. Moayyedi P, Surette MG, Kim PT, et al. Fecal microbiota transplantation induces remission in patients with active ulcerative colitis in a randomized controlled trial. Gastroenterology 2015;149:102-109, e6.

121. Paramsothy S, Paramsothy R, Rubin DT, et al. Faecal microbiota transplantation for inflammatory bowel disease: a systematic review and metaanalysis. J Crohns Colitis 2017;11:1180-1199.

122. Johnsen PH, Hilpüsch F, Cavanagh JP, et al. Faecal microbiota transplantation versus placebo for moderate-to-severe irritable bowel syn- drome: a double-blind, randomised, placebo-controlled, parallel-group, single-centre trial. Lancet Gastroenterol Hepatol 2018;3:17-24.

123. Halkjær SI, Christensen AH, Lo BZS, et al. Faecal microbiota transplantation alters gut microbiota in patients with irritable bowel syndrome: results from a randomised, double-blind placebo-controlled study. Gut 2018;67:2107-2115.

124. Borody T, Leis S, Campbell J, Torres M, Nowak A. Fecal microbiota transplantation (FMT) in multiple sclerosis (MS). Am J Gastroenterol 2011;106:S352.

125. Borody TJ, Rosen DM, Torres M, Campbell J, Nowak A. Myoclonusdystonia affected by GI microbiota? Am J Gastroenterol 2011;106:S351.

126. Kang DW, Adams JB, Gregory AC, et al. Microbiota transfer therapy alters gut ecosystem and improves gastrointestinal and autism symptoms: an open-label study. Microbiome 2017;5:10.

127.Li Q, Zhou JM. The microbiota-gut-brain axis and its potential therapeutic role in autism spectrum disorder. Neuroscience 2016;324:131139.

128. Evrensel A, Ceylan ME. The gut-brain axis: the missing link in depression. Clin Psychopharmacol Neurosci 2015;13:239-244.

129. Evrensel A, Ceylan ME. Fecal microbiota transplantation and its usage in neuropsychiatric disorders. Clin Psychopharmacol Neurosci 2016;14:231-237.

130. Borody TJ, Nowak A, Finlayson S. The GI microbiome and its role in chronic fatigue syndrome: a summary of bacteriotherapy. J Australas Coll Nutr Env Med 2012;31:3.

131. Frémont M, Coomans D, Massart S, De Meirleir K. High-throughput $16 \mathrm{~S}$ rRNA gene sequencing reveals alterations of intestinal microbiota in myalgic encephalomyelitis/chronic fatigue syndrome patients. Anaerobe 2013;22:50-56.

132. Finegold SM, Molitoris D, Song Y, et al. Gastrointestinal microflora studies in late-onset autism. Clin Infect Dis 2002;35(suppl 1):S6-S16.

133. Song Y, Liu C, Finegold SM. Real-time PCR quantitation of clostridia in feces of autistic children. Appl Environ Microbiol 2004;70:64596465.

134. Mulak A, Bonaz B. Brain-gut-microbiota axis in Parkinson's disease. World J Gastroenterol. 2015;21:10609-10620.

135. Bakken JS, Polgreen PM, Beekmann SE, Riedo FX, Streit JA. Treatment approaches including fecal microbiota transplantation for recurrent Clostridium difficile infection (RCDI) among infectious disease physicians. Anaerobe 2013;24:20-24.

136. Characterization of fecal microbiome changes after administration of PRIM-DJ2727 in Parkinson's disease patients. NIH U.S. National Library of Medicine. Available from URL: https:/clinicaltrials.gov/ct2/ show/NCT03026231 (accessed 10 July 2019).

137. Jiang ZD, Alexander A, Ke S, et al. Stability and efficacy of frozen and lyophilized fecal microbiota transplant (FMT) product in a mouse model of Clostridium difficile infection (CDI). Anaerobe 2017;48:110-114. 